\title{
BROADENING PARTICIPATION OF RURAL COMMUNITY COLLEGE TRANSFER STUDENTS IN STEM DEGREES AND CAREERS
}

\author{
Karen Paullet, Robert Morris University, paullet@rmu.edu \\ Debra Nakama, University of Hawaii Maui Colleg, debran@hawaii.edu \\ Natalya Bromall, Robert Morris University, bromall@rmu.edu \\ Diane Igoche, Robert Morris University, igoche@rmu.edu
}

\begin{abstract}
The Bureau of Labor Statistics projects that computer and information technology occupations are expected to grow by $12 \%$ from 2018 to 2028, this will translate to an additional 546,200 new positions. The demand for skilled workers in the computing fields needs to be addressed to fill these positions with talent from diverse backgrounds. The diversity in the computing workforce will enrich the innovations developed and enhanced while ensuring fairness and representation of all groups. Colleges, universities, and boot camps are creating avenues to close the skill gap. However, the STEM fields, including computing, are shown to have barriers to entry for typically underrepresented groups. The National Science Foundation (NSF) has funded a five-year project to support Robert Morris University's efforts to broaden participation of underrepresented groups in the STEM fields. This paper will highlight the beginning stages of this project and add to the discussion on engaging low-income, academically talented community college transfer students in computing majors (cyber-forensics, computer information systems, data analytics or information science). Additionally, this paper will address the significant role of mentoring to help students achieve success in the STEM fields.
\end{abstract}

Keywords: STEM-C, community college, transfer students, broadening participation, cyber security

\section{INTRODUCTION}

A Pittsburgh area workforce study reports that computer and mathematical occupations are expected to increase by 11 percent from 2015 to 2025 . This includes a 20 percent increase in information security analysts, and a 19 percent increase in computer systems analysts (Allegheny Conference on Community Development). The study mentioned above, projects that 89 percent of information technology job openings between 2015 and 2025 will require a bachelor's degree. Cybersecurity and data analytics are emerging as high growth fields in Pittsburgh's IT sector (Burning Glass Technologies, 2016). The Center for Cyber Safety and Education forecasts that by 2022, there will be 265,000 more cybersecurity jobs than there are skilled workers in the field in North America. (Frost \& Sullivan Center for Cyber Safety and Education, 2017). Four-year colleges should be engaging all appropriate avenues to prepare a skilled workforce to meet these needs.

Engaging community college transfer students holds promise as a pipeline into STEM $+\mathrm{C}$ bachelor degree programs. Student retention from this pipeline would be higher if four-year colleges can provide adequate academic and social supports to meet the community college transfer students' unique needs. Recruiting students from community colleges can strengthen the existing pathways to earning STEM degrees for students from underrepresented groups, including those who are low-income, first-generation, and minorities. These groups typically attend community colleges due to the lower cost of attendance.

\section{National Science Foundation Funded Effort}

RMU University received a five-year National Science Foundation (NSF) grant in February 2019, to support the recruitment, retention, and placement of academically talented, low-income, underrepresented community college transfer students from rural areas into computing careers. The project is known as the CIS (Computer and Information Systems) Cyber Scholars program. 
The project seeks to create a blueprint for other institutions to explore the community college transfer population as an untapped workforce for the STEM fields. This paper will introduce readers to the support mechanism employed to retain and successfully place CIS Cyber Scholars in computing related positions.

The CIS Cyber Scholars grant primarily recruits community college students in the southwest Pennsylvania area. A nationwide survey by the College Board shows that community college transfer students are usually commuter students who will obtain education from an institution close to family and employment.

\section{Community College Outreach}

With a high proportion of diverse and non-traditional students enrolled in rural community colleges, these institutions have a critical outreach role in expanding access to cybersecurity careers. Community colleges are central in focusing on this new wave of America's high school women and minorities in initiatives to improve their labor market prospects (Osterman, 2012). Moreover, early college cybersecurity education at rural high schools that may not have access to cybersecurity courses focusing on women and minorities presents an important opportunity to improve the economic security for a wider and diverse range of students they serve (Nakama 2016).

Community colleges play a critical role in providing access in higher education. However, there are a multitude of factors beyond the individual preferences of community college students and the institutional characteristics of community colleges that continue to face significant challenges related to producing equity in educational outcomes for the wide range of students that they currently serve (Penner-William, et.al., 2010). Moreover, the community college connection to high schools is broad in scope and continues to increase via a number of models that offer early college admit options (Morest, 2006). Community colleges are central in focusing on this new wave of America's high school women and minorities in initiatives to improve their labor market prospects. Community college outreach serve as the critical bridge to address the access and persistence of women and minorities in cybersecurity careers (Nakama, 2016).

\section{Cyber Scholars Program Objectives}

The CIS Cyber Scholars Program is equipping low-income, academically talented community college transfer students with a demonstrated financial need with the economic, academic, and practical support to advance into STEM careers or graduate school by:

1. Recruiting 30 low-income, academically talented undergraduate students who major in Cyber-Forensics, Computer Information Systems, Data Analytics, or Information Science into the CIS Cyber Scholars Program. CIS Cyber Scholars are recruited from area community colleges. Applications are also accepted from transfer students who apply directly to RMU University. The CIS Cyber Scholars Program provides scholarships for students in their third and fourth years of study. The project recruits students from underrepresented groups in the computing fields, including women, minorities, individuals from rural regions, and first-generation college students.

2. Through the CIS Cyber Scholars Program, 100 percent of scholars will graduate with a STEM degree. The CIS Cyber Scholar Program supports scholars to achieve their best academic performance. The program has instituted a new 8-week course called IntegrateRMU. The course introduces transfer students and cohorts to the appropriate systems, resources, and support mechanisms for their success in the University. Activities to support retention of scholars include a faculty-student mentoring program, project-based active learning, course-embedded service-learning projects, among others.

3. Through the CIS Cyber Scholars Program, 100 percent of enrolled scholars will enter STEM careers or graduate programs. RMU currently places 93 percent of CIS graduates into STEM career pathways. The CIS Cyber Scholars are being prepared to take on post-graduation opportunities including graduate studies, professional certification training, and STEM careers through presentations by industry professionals, career fairs, faculty mentoring, and Career Center presentations. 


\section{LITERATURE REVIEW}

As this is an ongoing study, this section shows highlights the need for each proposed support mechanism through a survey of the current literature.

Transfer students enter four (4) year institutions with different retention and support needs than those of traditional undergraduate students. Institutions must provide tailored supports that address the unique academic, financial, and persistence obstacles they face (Handel \& Williams, 2012). Studies have shown that all students, including those from underrepresented populations, benefit from meaningful assignments, positive student-faculty interaction, inclass collaboration, and opportunities to see and connect the relevance of course work to the real-world (GrantVallone, 2004; Baker, Hovey, \& Thompson, 2014).

\section{Academic Support Structure}

The CIS Cyber Scholars Program applies evidence-based, high-impact retention and support strategies; the program investigates whether each approach is effective in retaining and placing community college transfer students.

Transfer Experience Course (IntegrateRMU): While RMU accepts a large number of transfer students each year, RMU's new student orientation and first-year experience course primarily serves only first-time freshmen students. Scholars are enrolled in the IntegrateRMU course to ensure that the transfer students begin their program with a solid foundation. The IntegrateRMU course is an eight-week, one-credit-hour course. A transition course for transfer students creates a dedicated space that meets the particular support needs that are particular to transfer students (Johnson, Sunderraman, \& Bourgeois, 2018). Transfer students are often unaware of the support services available to them. A course like IntegrateRMU strengthens students' connections to available support (Herrera \& Jain, 2013).

The Integrate RMUcourse integrates transfer students into the RMU community as well as addresses challenges faced by low-income students transferring from community colleges. Ononye and Bong(2018) show that lowincome transfer students will stay at schools that provide targeted student support, and mentoring opportunities and have better educational outcomes. Studies have been conducted on transfer orientation programs for transfer students but there is a need for specific programs that support computing majors from community colleges (Rhine, Milligan, \& Nelson, 2000; Wang, Chan, Soffa, \& Nachman, 2017; Wetzel \& Debure, 2018).

The creation of a dedicated integration program allows an institution to understand the unique and changing needs of transfer students. Institutions cite lack of faculty resources for the implementation of a dedicated integration program (Kuh, 2008). The project team is designing the course to be available via face-to-face, hybrid and online delivery media. This will ensure sustainable offerings in semesters to come.

\section{STEM Faculty-Student Mentoring}

Community college transfer students, and especially those from underrepresented groups, benefit from strong connections with faculty members who can serve as engaged role models. Students with backgrounds similar to those of CIS Cyber Scholars who were matched with faculty mentors had higher college retention and graduation rates than non-mentored students (Kendricks \& Nedunuri, 2013). All CIS Cyber Scholars are assigned to a faculty advisor when they are admitted to the program. Advisors help students select and register for courses.

At the beginning of each school year, an orientation meeting is held with new scholars and their mentors in attendance. Mentors and students also meet at least once monthly during the school year. At RMU, faculty mentors and students use Student Success Collaboration software to monitor student persistence and progression patterns and identify at-risk students so that on-time intervention can occur. In the event of an unsuccessful mentorship match, new matches are made as needed.

A study conducted by Glass (2013) shows that a lack of mentors is an important factor in few girls studying cybersecurity in middle school, high school and at the collegiate level. If the mentor projected a stereotypical image of a "geek or nerd", girls were less like to believe in their success in the field. The success of role models for young women is needed to help girls succeed in cybersecurity. 
Willis-Ford (2018) conducted a quantitative study to gain an understanding into why women have a lower retention rate than men in the cybersecurity industry. As part of the study the author analyzed the impact of mentorship or lack thereof. The lack of mentors for women in cybersecurity is an important factor into low retention rates of women in STEM.

When students have positive mentoring experiences they are more likely to do better in their studies (Crisp, et. Al. 2009). By implementing mentoring programs for STEM education, institutions can expect to see increased student engagement and retention (Kuh, 2018). Underrepresented students including those from low-income backgrounds particularly benefit from mentoring initiatives (Stolle-McAllister, et.al., 2011). Students that are being recruited for the Cyber Scholars program must be a transfer student from rural community colleges who are academically talented and economically challenged.

\section{Course-Embedded Service Learning}

Undergraduate service-learning is identified as a high impact educational practice that promotes undergraduate retention and academic success (Kuh, 2008). Through service-learning, students develop a STEM identity and increase their commitment to STEM study, which promotes retention (Kapoor \& Gardner-McCune, 2018). RMUs Student Engagement Transcript Program (SET) generates a student engagement transcript, which provides an endorsement of a student's leadership roles, community service hours, study abroad experiences, exposure to internships and other forms of engagement. The service-learning opportunities in the program align with SET requirements to support CIS Cyber Scholars in completing requirements that are attuned to computing employers' needs.

\section{Enhanced Active Learning in Key Courses}

Many CIS courses have recently revised syllabi to increase active learning, in which hands-on, real-world, small group, case-based, and problem-solving teaching and learning methods replace traditional lectures (Freeman, 2014). While Graham found that active learning in introductory courses was particularly valuable in STEM retention (Graham, 2013), RMU will apply active learning to third-year courses that commonly enroll new transfer students, thereby serving as their introduction to CIS courses at RMU.

\section{CONCLUSION}

Researchers, policy makers, scientific funding agencies, businesses/industries, educational institutions and practitioners are investing significantly in the recruitment and retention of the cybersecurity skills pipeline shortage that has been growing worldwide. Bringing an intersectionality lens to understanding underrepresented students provides a clearer view of how to retain rural, underrepresented students into the cybersecurity pipeline. From the convergence of intersectionality and education, it is critical to use an inquiry of praxis sensitivity to space, place and geography as a tool for social justice and broadening participation in cybersecurity (Collins, P. H. \& Bilge, 2016; Grazanka, P. R., 2014). It our hope that this research can serve to assist others on broadening participation in cybersecurity within the confines of large, bureaucratic, often patriarchal systems.

\section{FUTURE WORK}

The CIS Cyber Scholars Program is in its early stages. Its first cohort consists of six (6) students enrolled in the CIS Cybersecurity and Digital Forensics degree. The project team will continue to report on the application of these support structures and the creation of other mechanisms as they occur. Strategies to strengthen community college transfer students' pathways to undergraduate success have been rigorously investigated in both STEM and nonSTEM fields but have yielded mixed results about how to deploy four-year colleges' resources most effectively to support these undergraduates. The CIS Cyber Scholars Program will explore whether targeted supports can effectively improve retention, graduation, and job and post-graduate studies placement rates for community college transfer students. The CIS Cyber Scholars Program will also generate knowledge on the role of engaged learning and directed support efforts, in retaining and placing underrepresented students in the STEM workforce. The steps listed in this paper can be a starting point for other institutions with a community college pipeline. 


\section{ACKNOWLEDGEMENTS}

The material in this submission is based upon work supported by the National Science Foundation under Grant \#1834083. Any opinion, findings, conclusions, or recommendations expressed in this material are those of the authors and do not necessarily reflect the views of the National Science Foundation.

\section{REFERENCES}

Allegheny Conference on Community Development. (2017). Inflection point 2017-2018. Supply, demand and the future of work in the Pittsburgh region. Retrieved from https://www.alleghenyconference.org/wpcontent/uploads/2017/12/018_InflectionPoint.pdf

Baker, L., Hovey, C., \& Thompson, L. (2014). Results of a large-scale, multi-institutional study of undergraduate retention in computing.

Crisp, G., \& Cruiz, I. (2009). Mentoring college students: A critical review of the literature between 1990 and 2007. Research in Higher Education, 50(6), 525-545.

Freeman, S. (2014). Active learning increases student performance in science, technology, engineering and mathematics. Proceedings of the National Academy Sciences of the United States of America, 8410-8415.

Frost \& Sullivan. Center for Cyber Safety and Education. (2017). 2017 Global Information Security Workforce Study: Benchmarking workforce capacity and response to cyber risk.

Graham, M. (2013). Increasing persistence of college students in STEM. Science, 1455-1456.

Grant-Vallone, E. (2004). An analysis of the effects of self-esteem, social support and services on students' adjustment and commitment to college. Journal of College Student Retention, 255-274.

Handel, S., \& Williams, R. (2012). The promise of the transfer pathway: Opportunity and challenges for community college students seeking the baccalaureate degree. The Initiative on Transfer Policy and Practice.

Herrera, A., \& Jain, D. (2013). Building a Transfer-receptive culture at four-year institutions. New Directions in Higher Education, 51-59

Johnson, W., Sunderraman, R., \& Bourgeois, A. (2018). Performance impact of computer science course load and transfer status. Proceedings of the $49^{\text {th }}$ ACM Technical Symposium of Computer Science Education, (p. 1076).

Kapoor, A., \& Gardner-McCune, C. (2018). Understanding professional identities and goals of computer science undergraduate students. $49^{\text {th }} A C M$ Technical Symposium.

Kendricks, K., \& Nedunuri, K.A. (2013). Minority student perceptions of the impact of mentoring to enhance academic performance in STEM disciplines. Journal of STEM Education, Innovations and Research, 3846.

Kuh, G. (2008). High-impact educational practices: What they are, who has access to them, and why they matter.

Morest, V.S. \& Karp, M.M. (2006). Twice the credit, half the time? The growth of dual credit at community colleges and high schools. Defending the Community College Equity Agenda, pp. 223-245.

Nakama, D.A. (2016). Community colleges outreach role in cybersecurity. National Cybersecurity Institute Journal, 3(2), pp. 35-39.

Ononye, L.C. \& Bong, S. (2018). The study of the effectiveness of a scholarship grant program on low-income engineering technology students. Journal of STEM Education, 18(5), pp. 26-31.

Osterman, P. (2012). The promise, performance, and policies of community colleges. Reinventing Higher Education: The Promise of Innovation. Pp. 129-158.

Penner-Williams, J., Perez, D., Worthen, D.G., Herrera, S., \& Murphy, K., (2010). A classic approach to collaboration: Documenting an multi-state university and multi-school district partnership. Collaboration in Education. pp. 161-167. New York, NY: Routledge.

Rhine, T., Milligan, D., \& Nelson, L. (2000). Alleviating transfer shock: Creating an environment for more successful transfer students. Community College Journal of Research and Practice, 443-453.

Stolle-McAllister, K., Sto Domingo, M.R., \& Carrillo, A. (2011). The Meyerhoff way: How the Meyerhoff scholarship program helps Black students succeed in the sciences. Journal of Science Education and Technology, 20(1), 5-16.

Wetzel, L., \& Dubure, K. (2018). The role of faculty in fostering STEM transfer student success. Journal of College Science Teaching, 42-46. 